\title{
PARÂMETROS FÍSICOS DO SOLO EM DIFERENTES SISTEMAS DE MANEJO CONVENCIONAL, MUNICÍPIO DE RESERVA - PR
}

\author{
Adalberto Alves Pereira ${ }^{1}$ \\ Edivaldo Lopes Thomaz ${ }^{2}$
}

RESUMO: O objetivo deste trabalho é avaliar o efeito da pecuária extensiva e do plantio convencional nos parâmetros físico-hídricos do solo comparando-os com uma área de floresta. As áreas foram divididas em terço superior, terço médio e terço inferior, em cada seção coletaram-se quatro amostras indeformadas por camada de solo $(0,0-0,05 ; 0,05-0,15 ; 0,15-0,30 \mathrm{~m})$, resultando em 36 amostras por área, para avaliação da densidade e estabilidade de agregados do solo. $A$ resistência mecânica foi estimada utilizando um penetrômetro de impacto e para mensuração da infiltração utilizou-se um infiltrômetro de tensão. A pastagem apresentou os maiores valores de densidade e resistência mecânica, o que demonstra a compactação da área. Inversamente à densidade e resistência o diâmetro médio de agregados mostrou boa agregação na pastagem com presença de agregados maiores de 2,0 $\mathrm{mm}$ e índice de estabilidade de agregados superior a $98 \%$ na camada superficial. O manejo convencional contribui para a baixa densidade e resistência mecânica do solo, mas influencia de maneira negativa na agregação. Conclui-se desta forma, que pastejo mal manejado e sem controle de lotação animal tem provocado a compactação do solo e o manejo convencional apresenta degradação da estrutura do solo devido à baixa estabilidade de agregados.

Palavras-chave: pastagem extensiva; compactação do solo; estabilidade de agregados; infiltração.

\section{SOIL PHYSICAL PARAMETERS ON THE DIFFERENT TILLAGES SYSTEMS, RESERVA CITY, PARANÁ STATE}

\begin{abstract}
The objective is to evaluate the effect of extensive cattle and conventional tillage on the soil physical-hydric parameters comparing them to a forest area. The areas were divided into upper third, middle third and lower third in each section-collected four undisturbed samples of soil layer $(0,0-0,05 ; 0,05-0,15 ; 0,15-0,30 \mathrm{~m})$, resulting in 36 samples per area, for evaluating the density and aggregate stability of soil. The mechanical resistance was estimated using a impact penetrometer and to measure infiltration was used one tension infiltrometer. The pasture presented the highest values of density and mechanical resistance in all layers evaluated, which demonstrate the compactation in area. Inversely the density and resistance, the average diameter of aggregates showed good aggregation in pasture with presence of aggregates larger than 2,0 $\mathrm{mm}$ and aggregate stability index greater than $98 \%$ in the surface. The conventional management contributes to low density and soil resistance but negatively affects the aggregation. Thus concludes, that grazing mishandled and no stocking control has caused soil compaction and the conventional management features degradation of soil structure due to low aggregate stability.
\end{abstract}

Keywords: extensive grazing; soil compaction; aggregate stability; infiltration.

1. Universidade Estadual do Centro-Oeste (adalbertoalvespereira@yahoo.com.br).

2. Universidade Estadual do Centro-Oeste (ethomaz@brturbo.com.br). 


\section{INTRODUÇÃO}

O manejo do solo deve oferecer condições favoráveis ao crescimento e desenvolvimento das culturas, mas se realizado de forma inadequada, eles podem promover a degradação da qualidade física do solo, com restrições ao crescimento radicular (KLUTE, 1982).

Por serem os parâmetros do solo intrinsecamente complexos, quando se insere na análise a variável manejo do solo, esta complexidade amplia-se, gerando comportamentos que muitas vezes não podem ser previstos de maneira linear.

Neste contexto a física de solo vem contribuir na avaliação e manutenção da qualidade ambiental dos solos, já que, a física de solos estuda e define, qualitativa e quantitativamente, as propriedades físicas, buscando compreender seu comportamento e suas relações com o uso e manejo (REINERT e REICHERT, 2006).

Os atributos físicos hierarquicamente mais importantes no estudo dos solos são textura e estrutura (REINERT e REICHERT, 2006). A textura demonstra o tamanho das partículas minerais que formam o solo, já a estrutura representa como estas partículas se organizam formando os agregados, além de definir a geometria dos espaços porosos (REICHARDT e TIMM, 2012). Em conjunto estas características podem influenciar nos teores de água e ar presentes no interior do solo e no crescimento de vegetais, além de influenciarem outras qualidades físicas como: densidade e porosidade do solo.

Estas características têm grande influência na erodibilidade dos solos, que é a capacidade do solo em resistir à erosão, pois partículas grosseiras como areia resistem ao transporte e solos de textura fina como os argilosos suportam a desagregação, tendo os solos com alto percentual de areia fina ou silte as maiores susceptibilidades aos processos erosivos.

A textura de um solo não sofre alterações em um curto espaço de tempo diferentemente da estrutura que pode sofrer modificações ocasionadas pelas práticas de uso e manejo. Por apresentar rápidas modificações tanto no tempo como no espaço a estrutura do solo vem sendo utilizada como indicador da qualidade ambiental.

Dexter e Youngs (1992) argumentam que a quantificação e a compreensão das alterações físicas do solo devidas ao seu uso e manejo são fundamentais para o estabelecimento de sistemas agrícolas sustentáveis.

Buscando-se contribuir para um melhor entendimento das relações solo-produção agrícola dentro do sistema ambiental, além de corroborar na conservação dos solos e da água no âmbito das propriedades agrícolas de produção familiar ou em solos de baixa aptidão agrícola, o objetivo deste estudo foi avaliar o efeito da pecuária extensiva e do plantio convencional sobre os parâmetros físico-hídricos do solo.

\section{MATERIAL E MÉTODO}

\section{- Localização e características da área de estudo}

Este trabalho foi realizado na bacia hidrográfica do Arroio Palmeirinha, município de Reserva - PR. A bacia localiza-se entre as coordenadas $24^{\circ} 31^{\prime} 28^{\prime \prime S}$ e $24^{\circ} 33^{\prime} 21^{\prime \prime}$; ; $50^{\circ} 53^{\prime} 50^{\prime \prime} \mathrm{W}$ e $50^{\circ} 56^{\prime} 16^{\prime \prime}$ W (Folha SG.22-X-A-IV-1) e apresenta área total de 774 há (Figura 01). 
Dentre as principais formas de uso na bacia, o manejo com pastagens extensivas de baixa tecnologia predomina, ocupando $54 \%(420,74 \mathrm{ha})$ da área total (Figura 02). As áreas de floresta e vegetação natural somam 19\% (144,63 ha), áreas agrícolas 16\% (120,53 ha) e em menor proporção, a silvicultura com 11\% (88 ha) (PEREIRA, 2013).

Foram escolhidas três áreas para realização deste estudo, sendo: uma área de pastagem extensiva, uma área cultivada com feijão preto (Phaseolus Vulgaris L.); e uma com floresta (Tabela 01). A pastagem foi escolhida por ocupar a maior área da bacia, a escolha da cultura do feijão se deu por ser esta a principal cultura praticada no município, com produção de cerca de 28.200 toneladas, tornando-o o terceiro maior produtor do estado do Paraná e o décimo maior do país, com participação de $0,73 \%$ do total nacional (SALVADOR, 2011). A área de floresta foi utilizada como área controle.

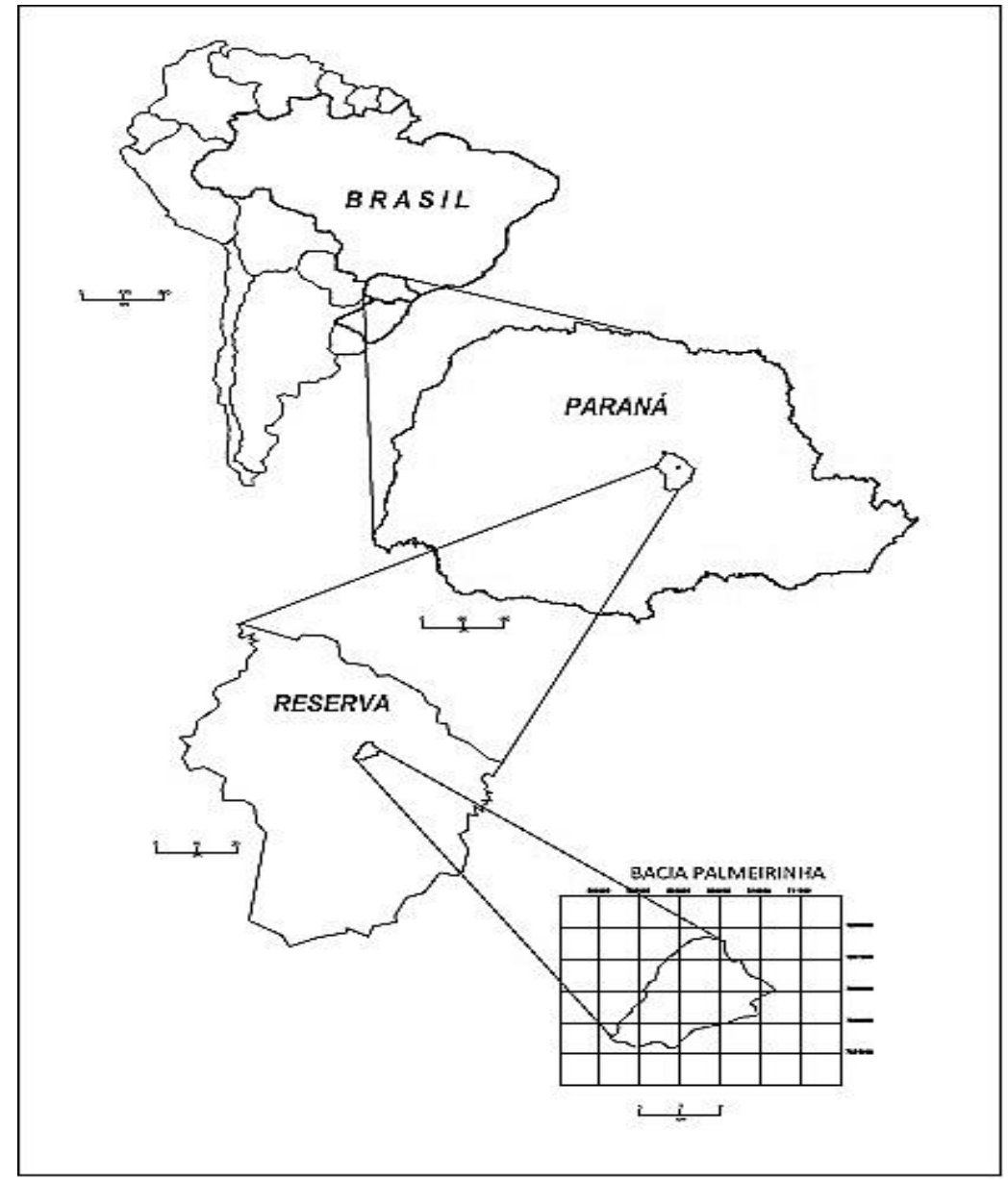

FIGURA 01: Localização da área de estudo.

Fonte: Pereira (2013). 


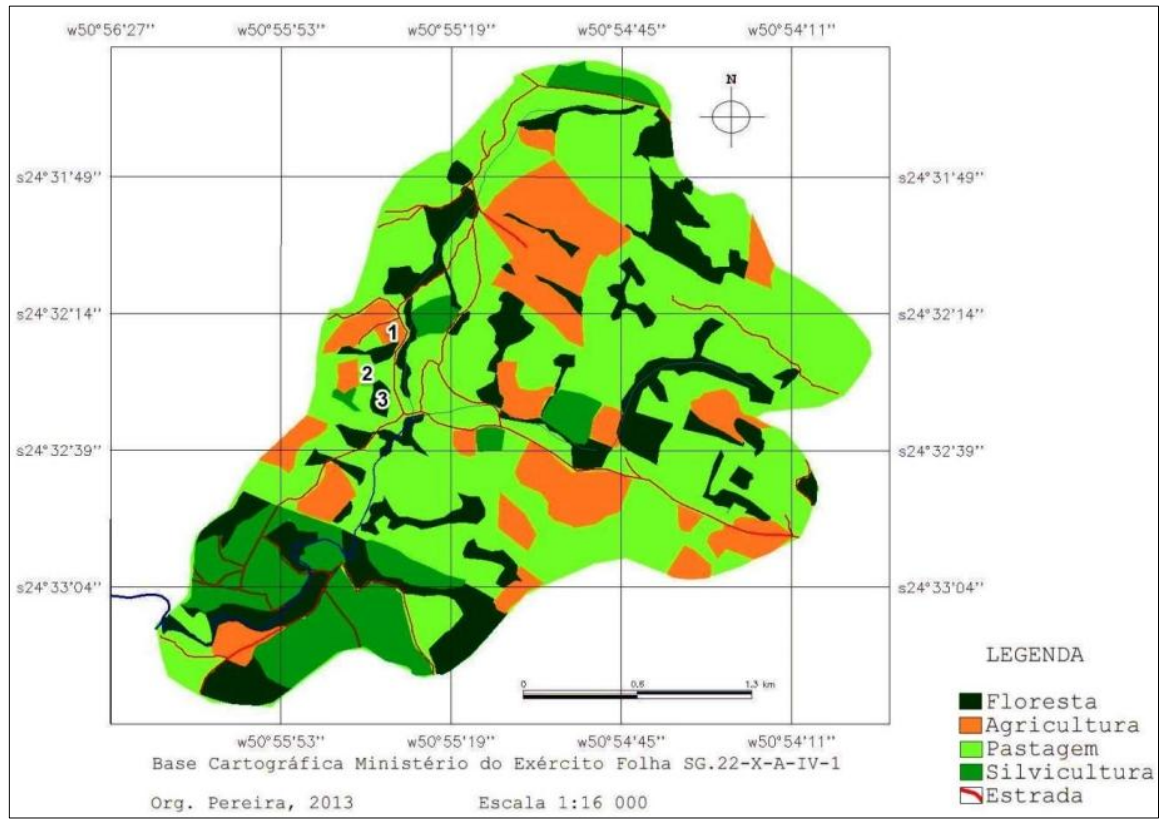

FIGURA 02: Uso do solo na bacia hidrográfica do Arroio Palmeirinha. 1 - Área de Plantio Convencional (PC); 2 - Área de pastagem (PE); 3 - Área de Floresta (FT). Fonte: Pereira (2013).

TABELA 01. Características de manejo nas áreas estudadas.

\begin{tabular}{|c|c|c|}
\hline Área & Tamanho (ha) & Características de manejo \\
\hline $\begin{array}{l}\text { Plantio } \\
\text { Convencional } \\
\text { (PC) }\end{array}$ & 02 & $\begin{array}{l}\text { Vertente retilínea. } 10 \text { anos de cultivo (2002-2012) com rotação } \\
\text { entre feijão e milho, manejo tradicional, uma aração e duas } \\
\text { gradagens com implementos à tração animal para plantio em } \\
\text { linha e colheita manual. Declividade variando entre } 6^{\circ} \text { e } 12^{\circ} \text {. }\end{array}$ \\
\hline $\begin{array}{l}\text { Pastagem } \\
\text { (PT) }\end{array}$ & 03 & $\begin{array}{l}\text { Vertente côncavo-retilínea. Utilizada há } 10 \text { anos (2002-2012) } \\
\text { como pastagem com Brizantão (Brachiaria brizantha cV } \\
\text { Marandú) sem manejo no período, lotação de } 3 \text { animais por } \\
\text { hectare. Declividade entre } 6^{\circ} \text { e } 12^{\circ} \text {. }\end{array}$ \\
\hline Floresta (FT) & 02 & $\begin{array}{l}\text { Vertente côncavo-convexa. Floresta secundária, caracterizada } \\
\text { pelos moradores locais como capoeirão, sem dados de } \\
\text { alteração no período } 1962-2012 \text {. Declividade entre } 6^{\circ} \text { e } 12^{\circ} \text {. }\end{array}$ \\
\hline
\end{tabular}

Fonte: Pereira (2013).

As áreas se encontram em altitude variando entre 780 e 820 metros, com clima Subtropical úmido (MINEROPAR, 2007), com verões frescos, geadas severas no inverno, sem estação seca, sendo que as temperaturas dos meses mais quentes são inferiores a $220 \mathrm{C}$ e dos meses mais frios inferiores a 18 C (ITCG, 2008).

Os solos das áreas foram caracterizados como Argissolo vermelho-amarelo eutrófico (EMBRAPA, 2013), de textura médio argilosa com $44 \% \pm 2$ de areia, $22 \% \pm 3$ de silte e $34 \% \pm$ $3 \%$ de argila e horizonte $A$ com $0,25 \mathrm{~m}$ de profundidade em média. 
TABELA 02: Propriedades químicas do solo nas diferentes áreas e profundidades avaliadas.

\begin{tabular}{|c|c|c|c|c|c|c|c|c|c|c|c|}
\hline \multirow[t]{2}{*}{ Área } & $\begin{array}{c}\mathrm{pH} \\
\left(\mathrm{CaCl}_{2}\right)\end{array}$ & & $\begin{array}{l}\text { MO } \\
(\%)\end{array}$ & $\begin{array}{r}\mathrm{C}^{-} \\
\text {(cmol }\end{array}$ & $\begin{array}{l}C \\
\left.d^{-3}\right)\end{array}$ & & $\begin{array}{l}\text { V } \\
\%)\end{array}$ & & $\begin{array}{l}M \\
\%)\end{array}$ & (mg & $\begin{array}{l}P \\
\left.\mathrm{dm}^{-3}\right)\end{array}$ \\
\hline & \multicolumn{11}{|c|}{$0,0-0,05 \mathrm{~m}$} \\
\hline PC & $5,00 \quad \pm 0,1$ & 3,31 & $\pm 0,16$ & 12,21 & $\pm 0,95$ & 54,87 & $\pm 6,42$ & 0,00 & \pm 0 & 10,17 & $\pm 7,10$ \\
\hline PT & $4,83 \pm 0,38$ & 3,40 & $\pm 0,41$ & 12,31 & $\pm 1,52$ & 60,43 & $\pm 6,84$ & 0,87 & $\pm 1,5$ & 2,50 & $\pm 1,51$ \\
\hline \multirow[t]{2}{*}{ FT } & $4,97 \pm 0,06$ & 3,94 & $\pm 0,66$ & 14,18 & $\pm 1,09$ & 62,13 & $\pm 0,72$ & 0,00 & \pm 0 & 10,33 & $\pm 11,67$ \\
\hline & \multicolumn{11}{|c|}{$0,05-0,15 \mathrm{~m}$} \\
\hline PC & $4,23 \pm 0,06$ & 2,82 & $\pm 0,14$ & 11,87 & $\pm 0,87$ & 42,03 & $\pm 8,12$ & 17,70 & $\pm 12,64$ & 3,70 & $\pm 1,65$ \\
\hline PT & $4,73 \pm 0,06$ & 3,26 & $\pm 0,34$ & 11,57 & $\pm 1,59$ & 54,07 & $\pm 8,67$ & 3,37 & $\pm 5,83$ & 2,33 & $\pm 0,8$ \\
\hline \multirow[t]{2}{*}{ FT } & $4,70 \quad \pm 0,1$ & 3,58 & $\pm 0,74$ & 15,33 & $\pm 3,03$ & 61,43 & $\pm 0,63$ & 0,80 & $\pm 1,38$ & 2,43 & $\pm 1,45$ \\
\hline & \multicolumn{11}{|c|}{$0,15-0,30 \mathrm{~m}$} \\
\hline PC & $3,93 \pm 0,06$ & 1,70 & $\pm 0,2$ & 13,43 & $\pm 1,35$ & 26,73 & $\pm 4,86$ & 47,70 & $\pm 10,81$ & 1,97 & $\pm 0,64$ \\
\hline PT & $4,53 \pm 0,06$ & 2,68 & $\pm 0,8$ & 10,88 & $\pm 0,71$ & 49,27 & $\pm 5,69$ & 4,23 & $\pm 6,24$ & 1,23 & $\pm 0,92$ \\
\hline FT & $4,63 \pm 0,15$ & 3,31 & $\pm 0,86$ & 13,78 & $\pm 1,9$ & 60,10 & $\pm 1,01$ & 1,30 & $\pm 2,25$ & 1,07 & $\pm 0,23$ \\
\hline
\end{tabular}

n:9. média \pm desvio padrão. PC - Plantio convencional; PT - Pastagem; FT - Floresta. MO Matéria orgânica; CTC - Capacidade de troca de cátions; V - Saturação de bases; M Saturação de alumínio; P - Fósforo.

Fonte: Pereira (2013).

Os solos podem ser caracterizados com acidez alta $(\mathrm{pH} \leq 5)$ (Tabela 02), especialmente, nas maiores profundidades, com capacidade de troca de cátions (CTC) classificada como moderadamente baixa (FAGERIA et al., 1999).

\section{- Avaliação dos parâmetros físicos}

As áreas foram divididas em três seções cada, sendo: terço superior, terço médio e terço inferior, em cada seção foram cavadas pequenas trincheiras nas quais se coletaram quatro amostras indeformadas por camada de solo $(0,0-0,05 ; 0,05-0,15 ; 0,15-0,30 \mathrm{~m})$, resultando em 12 amostras por camada e totalizando 36 amostras por área. Após coleta as amostras foram pesadas e secas em estufa em temperatura constante de $105^{\circ} \mathrm{C}$ durante 24 horas.

As amostras foram coletadas entre os meses de dezembro (2012) e janeiro (2013), momento em que as plantas (feijão) encontravam-se em estágio avançado de desenvolvimento, próximo ao período de colheita.

\section{- Densidade do solo (Ds) e umidade}

A densidade do solo (Ds) foi determinada com base em Embrapa (1997). A umidade foi mensurada em locais próximos de onde foram realizados os ensaios de resistência mecânica utilizando-se uma sonda TDR.

\section{- Resistência mecânica à penetração (Rp)}


A mensuração da resistência à penetração (Rp) foi realizada com a utilização de um penetrômetro de impacto (STOLF, 1991), foram realizadas quinze repetições em cada área, até a profundidade de 0,3 $\mathrm{m}$. Com a aplicação da equação 1, descrita por Stolf (1991) obteve-se a resistência à penetração em unidades de $\mathrm{mPa}$.

$R P=\left(\frac{M g h}{a x}\right)\left(\frac{M}{M+m}\right)+\left(\frac{M+m}{a}\right) g$

Onde: RP - resistência mecânica do solo à penetração $(\mathrm{mPa}) ; \mathrm{h}$ - altura de queda do cilindro de impacto $(\mathrm{m})$; $M$ - massa do êmbolo do penetrômetro $(\mathrm{kg}) ; \mathrm{m}$ - massa do penetrômetro $(\mathrm{kg})$; a - área da ponta do penetrômetro $(\mathrm{m}) ; \mathrm{x}$ - deslocamento do penetrômetro em cada impacto $(\mathrm{m})$; $\mathrm{g}$ - aceleração da gravidade $\left(\mathrm{m} \mathrm{s}^{-2}\right)$.

\section{- Estabilidade de Agregados}

A determinação do percentual de agregados foi realizada por via úmida de acordo com o método de Yoder (1936). Antes do peneiramento as amostras passaram por peneira de 8,0 $\mathrm{mm}$ e foram submetidas à imersão para umedecimento via capilar por 5 minutos.

O material foi agitado com movimentos ascendente e descendente por 20 minutos (40 rpm). Para peneiramento foram utilizadas peneiras com malhas de 4,$0 ; 2,0 ; 1,0 ; 0,5 ; 0,25 ; 0,125$ $\mathrm{mm}$. Depois de realizado o peneiramento, os agregados foram secos em estufa a $105^{\circ} \mathrm{C}$ durante 24 horas, em seguida estes passaram por pesagem, para determinação do percentual de agregados e realizou-se a correção do teor de areia, em que as frações areia e silte grosso foram passadas em peneira de $0,053 \mathrm{~mm}$.

A estimativa do Diâmetro Médio Ponderado de agregados (DMP) deu-se aplicando a equação 2, descrita por Youker e Macguines (1956) apud Kiehl (1979).

$\mathrm{DMP}=\sum(\mathrm{Cmm} \times \mathrm{P})$

Onde: DMP - Diâmetro médio ponderado $(\mathrm{mm}) ; \mathrm{Cmm}$ - Centro de classes de tamanhos dos agregados $(\mathrm{mm}) ; \mathrm{p}$ - Proporção do peso de cada fração de agregados em relação ao peso total da amostra (g).

O índice de estabilidade de agregados (IEA) foi estimado utilizando-se a equação 3, descrita por Perin et al. (2002).

$$
I E A=\frac{(P s-w p 0.250-\text { areia })}{\left(P s^{-} \text {Areia }\right)} \times 100
$$

Onde: IEA - Índice de estabilidade de agregados (\%); Ps - massa da amostra seca (g); wp0,250 - é a massa dos agregados da classe $<0,250 \mathrm{~mm}(\mathrm{~g})$; Areia - massa de areia removida após a correção com peneira de $0,053 \mathrm{~mm}(\mathrm{~g})$.

\section{- Infiltração}

A infiltração da água foi determinada por meio de ensaios com utilização de um infiltrômetro de tensão a disco com diâmetro de $20 \mathrm{~cm}$. Foram realizados 9 repetições em cada área. Para se determinar a taxa de infiltração, utilizou-se a equação 4 descrita por Pott e De Maria (2003).

$$
I=q 60\left(\frac{D t^{2}}{D b^{2}}\right)
$$


Onde: I - Infiltração da água no solo $\left(\mathrm{mm} \mathrm{h}^{-1}\right) ; \mathrm{q}$ - fluxo constante de água do infiltrômetro de tensão ( $\left.\mathrm{mm} \mathrm{min}^{-1}\right)$; Dt - diâmetro do tubo do infiltrômetro de tensão (mm); Db - diâmetro da base do infiltrômetro de tensão (mm).

\section{- Análise estatística}

Utilizou-se o software Bioestat para análise estatística. Em princípio realizou-se análise descritiva (média, desvio padrão, coeficiente de variação) e avaliação da distribuição dos dados. Na sequência os dados foram submetidos à análise de variância (ANOVA), utilizandose delineamento inteiramente casualizado, com o tratamento na área (parcela) e as profundidades na subparcela. A comparação de médias foi feita pelo teste Tukey, a $5 \%$.

\section{RESULTADOS E DISCUSSÃO}

\section{- Densidade e Resistência mecânica}

As áreas PC e PT não diferiram entre si, mas diferiram da área FT na camada superficial $(0,0$ $0,05 \mathrm{~m}$ ). A partir da camada de 0,15 m, as áreas PC e FT apresentaram valores semelhantes (Figura 03).

A área PT apresentou os maiores valores de densidade e resistência mecânica do solo em todas as profundidades avaliadas, o que demonstra a compactação da área (Figura 03). A Rp apresentou valores elevados e restritivos ao crescimento das raízes (>2,0 $\mathrm{mPa}$ ) (Arshad et al. 1996, Secco 2003, Lapen et al. 2004), sendo que na camada mais inferior este valor $(6,88$ $\mathrm{mPa}$ ) foi três vezes superior à camada superficial.

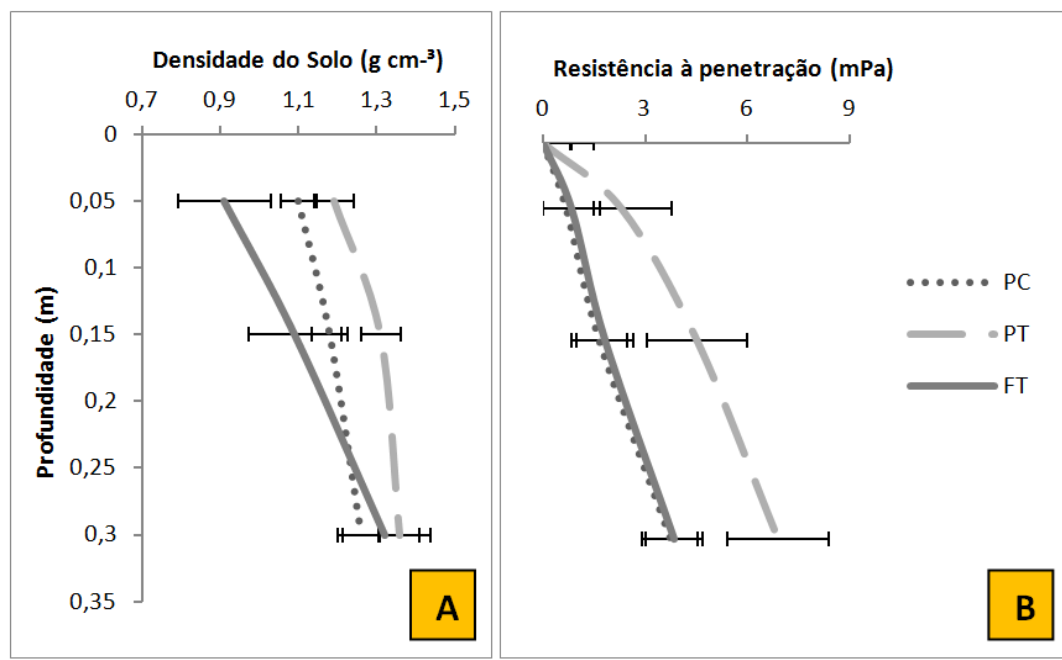

FIGURA 03: (A) Densidade do solo nas diversas áreas e profundidades; (B) Resistência mecânica à penetração nas diversas áreas e profundidades. PC - Plantio convencional; PT - Pastagem extensiva; FT - Floresta.

Fonte: Pereira (2013).

A falta de manejo e controle em relação à lotação de animais na área contribui para que esta apresente elevados índices de Ds e Rp. Moreira et al. (2005) afirmam que pastagens mal manejadas resultam em aumento na densidade do solo e na sua resistência à penetração devido ao excesso de carga animal ocasionado por diferentes lotações sobre as pastagens. 
Observa-se que a Rp aumentou aritmeticamente em profundidade na área PT, diferindo do exposto por Ralich et al. (2008) e Torres et al. (2012) que destacaram que os maiores valores de $R p$ ocorrem nas camadas superficiais $(0,0$ a 0,10 m). Estes valores elevados de $R p$ em profundidade devem ser resposta ao manejo em tempo contínuo (10 anos) e excessivo na área.

\section{- Estabilidade de Agregados}

Inversamente à Ds e Rp o DMP mostrou boa agregação na área PT com presença de agregados maiores de $2,0 \mathrm{~mm}$ e IEA superior a $98 \%$ na camada superficial (Figura 4). Este comportamento se deve ao predomínio das raízes de gramíneas nesta camada, com o aumento da profundidade e diminuição na densidade de raízes observa-se redução destes parâmetros.

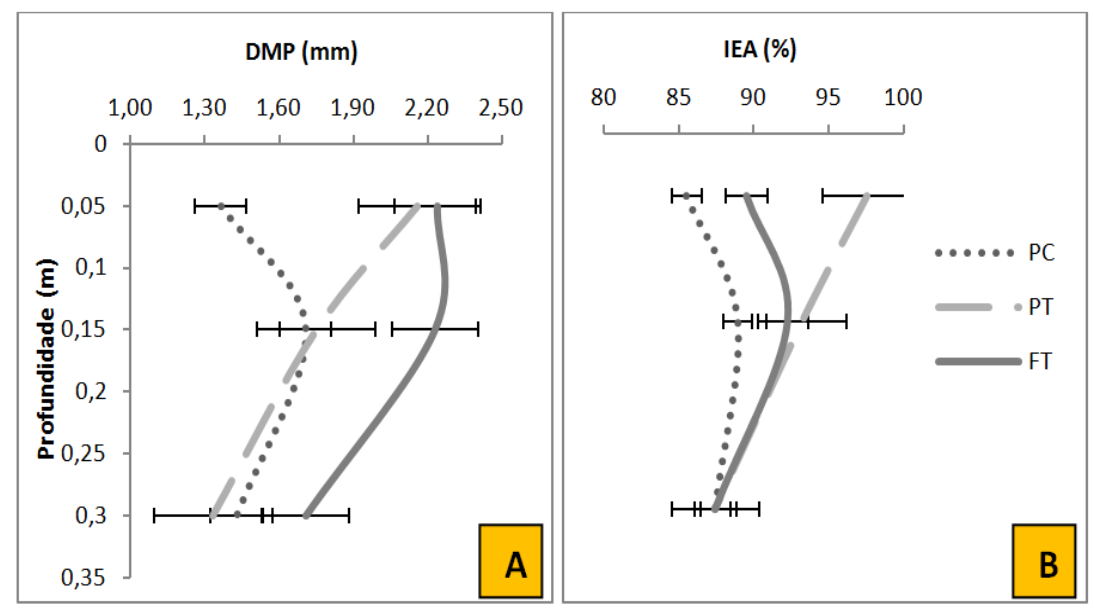

FIGURA 04: (A) Diâmetro médio ponderado de agregados (DMP) nas diversas áreas e profundidades; (B) Índice de Estabilidade de Agregados (IEA) nas diversas áreas e profundidades. PC - Plantio convencional; PT - Pastagem extensiva; FT - Floresta. Fonte: Pereira (2013).

Vários autores (TISDAL e OADES, 1982; SILVA e MIELNICZUK, 1997; SALTON et al. 2008, entre outros) demonstraram a eficiência das gramíneas na formação e estabilização de agregados devido ao papel das raízes, na liberação de exsudatos e crescimento e morte de tecidos que associado a ausência de revolvimento do solo, contribui efetivamente para formação de macroagregados estáveis.

O manejo convencional por romper a camada superficial através do uso de equipamentos para aração e gradagem do solo, contribui para que a área PC apresente baixa densidade e resistência mecânica, o que pode contribuir para o crescimento radicular, mas influencia de maneira negativa na estabilidade de agregados, fazendo com que esta área apresente os menores índices de DMP e IEA nas camadas superficiais (0,0-0,05 e 0,05-0,15 m).

Os valores obtidos neste estudo corroboram com Perusi e Carvalho (2008) que verificaram decréscimo no DMP na sequência Floresta - Pastagem - Cultura anual.

\section{- Infiltração}

A infiltração da água no solo é um bom indicador da qualidade física do solo, pois depende da forma, quantidade, tamanho e distribuição dos poros que são influenciados por atributos 
como densidade, resistência, porosidade, estabilidade de agregados entre outros, mas não pode ser obtida diretamente através da correlação com estes parâmetros físicos (MESQUITA e MORAES, 2004).

A área Pt apresentou a maior taxa de infiltração inicial, próximo de $95 \mathrm{~mm} \mathrm{~h}-1$, sendo também a que apresentou o menor valor de infiltração final, 2,3 $\mathrm{mm} \mathrm{h}-1$, resultando numa diferença de mais de 41 vezes entre a infiltração inicial e final (Figura 05).

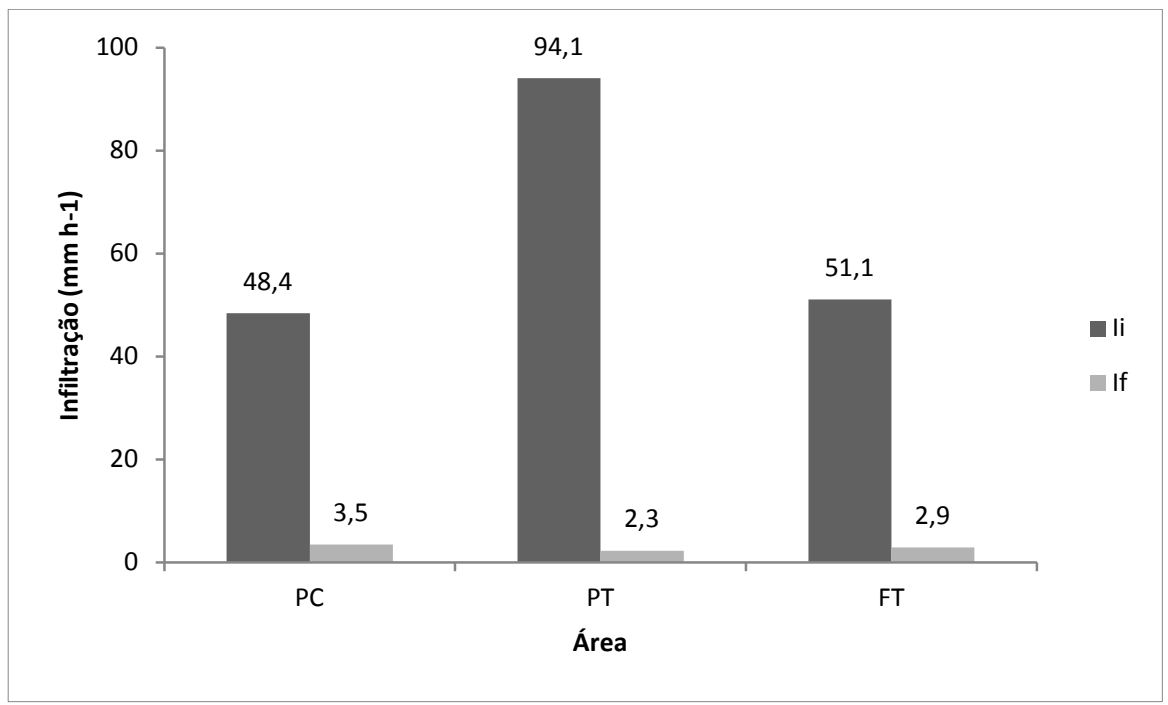

FIGURA 05: Taxas de infiltração inicial e final nas diversas áreas. li: Infiltração inicial; If: Infiltração final; PC - Plantio convencional; PT - Pastagem extensiva; FT - Floresta.

Fonte: Pereira (2013).

Esta diferença demonstra a complexa relação entre os parâmetros físicos da área, que no princípio, devido à presença de agregados grandes $(>2 \mathrm{~mm})$ e da elevada densidade de raízes que interligam os poros por meio da criação de caminhos preferenciais para o movimento da água no solo, tem infiltração elevada, após o atravessamento desta camada superficial, com o aumento da Ds e $\mathrm{Rp}$ associados à redução de raízes, tem seu fluxo reduzido significativamente.

A infiltração reduzida na área PC pode estar atrelada a menor estabilidade de seus agregados, pois com o impacto das gotas de chuva os agregados são rompidos e reduzidos a partículas finas resultando na formação de crostas superficiais e no adensamento de camadas inferiores do solo devido ao rearranjamento das partículas que vão ocupando os poros do solo, diminuindo assim a sua capacidade de infiltração.

\section{CONCLUSÃO}

A complexa relação entre os atributos físico-hídricos e o manejo dos solos fica evidente na realização deste trabalho, já que, parâmetros muitas vezes correlacionáveis nos demonstraram resultados divergentes em uma mesma área.

A ação das raízes das gramíneas na área PT contribuiu para que esta apresentasse agregados grandes e estáveis, mas o pastejo mal manejado e sem controle de lotação animal tem 
provocado a compactação do solo, o que pode comprometer a qualidade ambiental da bacia, já que, as pastagens ocupam mais de $50 \%$ de sua área total.

Em sentido inverso o manejo convencional na área PC apesar de apresentar índices baixos de $\mathrm{Rp}$ e Ds, tem sua estrutura degradada devido à baixa estabilidade de agregados representados pelos índices de DMP e IEA.

\section{AGRADECIMENTOS}

Agradecemos a Coordenação de Aperfeiçoamento de Pessoal de Nível Superior - CAPES, pela concessão de bolsa de estudos ao primeiro autor, sem a qual não seria possível a realização deste trabalho. Agradecemos também aos colegas Paulo Ângelo Fachin e Gustavo Toledo Peretto pelo auxílio nas atividades de campo e laboratório.

\section{BIBLIOGRAFIA}

ABIEC, Associação Brasileira das Indústrias Exportadoras de Carne. Pecuária Brasileira. São Paulo. Disponível em < http://www.abiec.com.br/3_pecuaria.asp>. Acesso em: 29 outubro 2014.

ARSHAD, M. A.; LOWERY, B.; GROSSMAN, B.. Physical tests for monitoring soil quality. In: DORAN, J. W.; JONES, A. J. (Eds). Methods for assessing soil quality. Soil Science Society of America, Madison, p.123-141, 1996.

CAMARGO, O. A.; ALLEONI, L. R. F. Compactação do solo e o desenvolvimento de plantas. Piracicaba: Escola Superior de Agricultura Luiz de Queiroz, 1997. 132 p.

EMBRAPA. Centro Nacional de pesquisa do solo. Manual de métodos de análise do solo. 2.ed. Rio de Janeiro: Bertrand Brasil, 1997. 212p.

EMBRAPA. Centro Nacional de Pesquisa do Solo. Sistema brasileiro de classificação de solos. 3.ed. Rio de Janeiro: Embrapa Solos, 2013. 353p.

FAGERIA, N. K.; STONE, L. F.; SANTOS, A. B. dos. Maximização da eficiência de produção das culturas. Brasília: Embrapa, Comunicação para Transferência de Tecnologia; Santo Antônio de Goiás: Embrapa Arroz e Feijão, 1999. 294p.

GUIMARÃES FILHO, C.. Paraná tem 2 milhões de hectares de pastagens subaproveitadas. Gazeta do Povo. Curitiba, 22 maio 2012. Disponível em < http://agro.gazetadopovo.com.br/arquivo/parana-tem-2-milhoes-de-hectares-de pastagenssubaproveitadas/>. Acesso em: 29 outubro 2014.

GUPTA, S. C.; ALMARAS, R. R.. Models to assess the susceptibility of soils to excessive compaction. Advances in Soil Sciences, New York, v.6, p.65-100, 1987.

IPARDES. Instituto Paranaense de Desenvolvimento Econômico e Social. Caderno Estatístico Município de Reserva. Curitiba, 2013. Disponível em: <www.ipardes.gov.br>. Acesso em: 29 outubro 2014.

KIEHL, E. J.. Manual de Edafologia: Relações solo planta. São Paulo: Ceres, 1979. 276p. 
KLUTE, A. Tillage effects on the hydraulic properties of soil: a review. In: VAN DOREN, D.M.; ALLMARAS, R.R.; LINDEN, D.R.; WHISLER, F.D. (Ed.) Predicting tillage effects on soil physical properties and processes. Madison: ASA, 1982. cap.3, p.29-43.

LAPEN, D.R.; TOPP, G.C.; GREGORICH, E.G.: CURNOE, W.E. Least limiting water range indicator of soil quality and corn production, eastern Ontario, Canada. Soil and Tillage Research, Washington, DC, v.78, n., p.151-170, 2004.

MESQUITA, M.G.B.F.; MORAES, S.O. A dependência entre a condutividade hidráulica saturada e atributos físicos do solo. Ciência Rural, Santa Maria, v.34, n.3, p.963-969, 2004.

MINEROPAR, Minerais do Paraná. Mapa de Vulnerabilidade Geoambiental do Estado do Paraná. Escala 1:650000. Curitiba, 2007. Disponível em <www.mineropar.pr.gov.br>. Acesso em: 04 outubro 2012

MINISTÉRIO DO EXÉRCITO - DEPARTAMENTO DE ENGENHARIA E COMUNICAÇÕES. Carta topográfica de Reserva - PR. Folha SG.22-X-A-IV-1. Escala 1: 50000. Brasília.

MOREIRA, J. A. A.; OlIVEIRA, I. P.; GUIMARÃES, C. M.; STONE, L. F. Atributos químicos e físicos de um Latossolo Vermelho distrófico sob pastagens recuperada e degradada. Pesquisa Agropecuária Tropical, Goiânia, v.35, n.3, p.155-161, 2005.

PEREIRA, A. A.; THOMAZ, E. L.. Hipsometria e Declividade da Bacia Hidrográfica do Arroio Palmeirinha, município de Reserva - PR, utilizando o Software Spring. In: XVI Simpósio Brasileiro de Sensoriamento Remoto, 2013. Foz do Iguaçu. Anais... Foz do Iguaçu: INPE, 2013, p.3494-3501.

PERIN, A.; GUeRRA, J. G. M.; TEIXEIRA, M. G.; PEREIRA, M. G.; FONTANA, A. Efeito da cobertura viva com leguminosas herbáceas perenes na agregação de um Argissolo. Revista Brasileira de Ciência do Solo, Viçosa, v. 26, p. 713-720, 2002.

PERUSI, M. C.; CARVALHO, W. A.. Comparação de métodos para determinação da estabilidade de agregados por via seca e úmida em diferentes sistemas de uso e manejo do solo. Geociências. v.27, n.2, p.197-206, 2008.

POTT, C. A.; DE MARIA, I. C.. Comparação de métodos de campo para determinação da velocidade de infiltração básica. Revista Brasileira de Ciência do Solo. Viçosa, v.27, n.1, p. 1927, 2003.

RALISCH, R.; MIRANDA, T. M.; OKUMURA, R. S.; BARBOSA, G. M. C.; GUIMARÃES, M. F. SCOPEL, E.; BALBINO, L. C. Resistência à penetração de um Latossolo Vermelho Amarelo do Cerrado sob diferentes sistemas de manejo. Revista Brasileira de Engenharia Agrícola e Ambiental. Campina Grande, v. 12, n.4, p. 381-384, 2008.

REICHERT, J.M.; REINERT, D.J.; BRAIDA, J.A. Qualidade dos solos e sustentabilidade de sistemas agrícolas. Revista Ciência e Ambiente, Santa Maria, v.27, p.29-48, 2003.

SALTON, J.C.; MIELNICZUK, J.; BAYER, C.; BOENI, M.; CONCEIÇÃO, P.C.; FABRÍCIO, A.C.; MACEDO, M.C.M.; BROCH, D.L. Agregação e estabilidade de agregados do solo em sistemas agropecuários em Mato Grosso do Sul. Revista Brasileira de Ciência do Solo, Viçosa, v.32, p.11-21, 2008. 
SALVADOR, C. A.. Análise da conjuntura agropecuária safra 2011/2012. Secretaria de Agricultura e Abastecimento do Paraná (SEAB-PR). Relatório técnico, 2011. Disponível em www.seab.pr.gov.br. Acesso em março de 2012.

SECCO, D. Estados de compactação e suas implicações no comportamento mecânico e na produtividade de culturas em dois latossolos sob plantio direto. 2003. 171 p. Tese (Doutorado em Agronomia) - Universidade Federal de Santa Maria, Santa Maria, RS.

SCHNEIDER, P. R.; GALVÃO, F.; LONGHI, S. J.. Influência do pisoteio de bovinos em áreas florestais. Revista Floresta, Curitiba, v. 19, n. 1, p. 19-23, 1978.

SILVA, I.F.; MIELNICZUK, J.. Avaliação do estado de agregação do solo afetado pelo uso agrícola. Revista Brasileira de Ciência do Solo, Campinas, v.21, p.313-319, 1997.

STOLF, R. Teoria e teste experimental de fórmulas de transformação dos dados de penetrômetro de impacto em resistência do solo. Revista Brasileira de Ciência do Solo, Campinas, v.15, n.2, p.229-235, 1991.

TISDALL, J. M.; OADES, J. M.. Organic matter and water-stable aggregates in soil. Journal Soil Science, Hagerstown, v.33, p.141-163, 1982.

TORRES, J. L. R.; RODRIGUES JUNIOR, D. J.; SENE, G. A.; JAIME, D. G.; VIEIRA, D. M. da S.. Resistência à penetração em área de pastagem de capim tifton, influenciada pelo pisoteio e irrigação. Bioscience Journal, Uberlândia, v.28, suplemento 1, p.232-239, 2012.

YODER, R.E. A direct method of aggregate analysis of soils and a study of the physical nature of erosion losses. Journal American. Society Agronomy. Madison, v.28, p.337-351, 1936. 